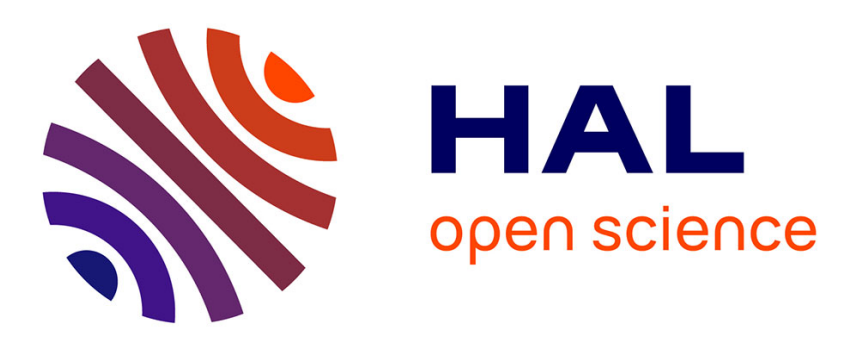

\title{
Design for remanufacturing: What performances can be expected?
}

\author{
Nicolas Tchertchian, Dominique Millet, Akram El Korchi
}

\section{To cite this version:}

Nicolas Tchertchian, Dominique Millet, Akram El Korchi. Design for remanufacturing: What performances can be expected?. International Journal of Environmental Technology and Management, 2012, 15 (1), pp.28 - 49. 10.1504/IJETM.2012.045151 . hal-01064712

\section{HAL Id: hal-01064712 \\ https://hal.science/hal-01064712}

Submitted on 17 Sep 2014

HAL is a multi-disciplinary open access archive for the deposit and dissemination of scientific research documents, whether they are published or not. The documents may come from teaching and research institutions in France or abroad, or from public or private research centers.
L'archive ouverte pluridisciplinaire HAL, est destinée au dépôt et à la diffusion de documents scientifiques de niveau recherche, publiés ou non, émanant des établissements d'enseignement et de recherche français ou étrangers, des laboratoires publics ou privés. 


\title{
Design for Remanufacturing: What performances can be expected?
}

\author{
Nicolas Tchertchian*, Dominique Millet \\ 'Ecodesign and Optimization of Product' Lab \\ S U P M E C A - Toulon, Quartier Mayol, Maison des Technologies 83000 \\ Toulon, France \\ E-mail : nicolas.tchertchian@supmeca.fr
}

\section{A. El Korchi \\ ENSA AGADIR, BP 1136, \\ Agadir, Morocco}

\begin{abstract}
The objective of this report is to supply first of all a state of the art on the consideration of the remanufacturing on one hand in the ecodesign methods and on the other hand in the reverse supply chain management (RSC). These states of the art show that the available methods of ecodesign take into account little the potentialities of the remanufacturing notably because of the difficulty considering products with multiple life cycles (notion of upgradability). They show on the other hand that the RSC management and the ecodesign methods are considered rarely simultaneously. A case study conducted on an espresso machine completes these states of the art to accentuate the various dimensions of the remanufacturing problem. All these elements reveal the necessity of giving to the design team, a method helping to develop new concepts of remanufacturable systems.
\end{abstract}

Key words: Eco-Design, Remanufacturing, LCA, Economic Assessment, DfX, RSC

Biographical notes:

Nicolas Tchertchian is graduate in mechanical engineering and a $\mathrm{PhD}$ candidate at Ecole Centrale de Paris, in LISMMA laboratory at Ecodesign \& Optimisation of Product (EOP) division manage by Professeor Domninique Millet.

His field of research is Ecodesign of system, LCA, Eco-innovation and Design for Remanufacturing.

Dominique Millet is a full professor at Department of Design of Mechanical Systems, SUPMECA Toulon. He received his Ph.D. in Design Sciences from ENSAM of Paris in 1995 and his 'Habilitation à Diriger des Recherches' from INPG in 2003. His research interests include Design and Ecodesign Methodology. He has published over 100 technical papers in major international journals and conferences.

\section{DFX Methodology}




\section{Tchertchian N, Millet D \& El Korchi A}

"Design for X" (DfX) deals with conflicts between increasingly many constraints in the design stage. "Design for" means the general objective which guides the step of design and its processes. They are systematic approaches of design which treat related questions with manufacture, assembly/disassembling, reliability, the cost... During last decades, many research teams developed DfE methods "Design for Environment" aiming at the end-of-life optimization of the product (design for disassembling, reduce, recycling, remanufacturing, re-use, etc.). Those have jointly to evaluate one (or several) environmental criteria (mass, recycling rate, energy saving...) in combination with several economic criteria (time of disassembling, profit of recycling, etc.).

\section{Design for Disassembly and Recycling}

Dismantling and recycling are increasingly important in the majority of the industrialized countries because of the increase of amount of products put in discharge. The dismantling of the worn products is regarded as necessary for a recycling economically viable with current technologies of reprocessing.

The purpose of DfD is to integrate the constraints of product dismantling in order to facilitate its treatment at the end of the life: extraction of components or modules being able to be re-used, of dangerous substances in order to be able to treat them specifically, of the components to incinerate... dismantling makes it possible to be able to achieve the goal of "recycling" and supports also the taking into account of other scenarios of valorization, in particular the re-use of components or subsets.

The transformation of the products at the end of the lifetime for the re-use of the components and the valorization of the secondary materials and energy saving, constitute a means of limitation of the environmental issues but also an economic and social development strategy. To reach this challenge, several research showed the need for breaking up the products upstream to every process of valorization. The study of Haoues (2006) focused on the contribution to the integration of dismantling and recycling constraints as of the first phases of products development process. A model made up of minimal data from which the disassemblability as soon as possible in the process of design can be defined: this sequence of dismantling is used thereafter as reference for the phase of detailed design.

So that a component is disassembled of a product at the end of life, Haoues (2006) considers that three conditions must be checked:

- Valorisability: This first condition depends primarily on materials constitutive of the component,

- Accessibility: It is the condition which depends essentially on the structure of the product and on the dimensions around valorisables components,

- Separability: This condition depends primarily on the types of joints between components.

Indicators of dismantling assessment for valorization were also elaborate: Material Indicator, Structural Indicator and Connection Indicator corresponding respectively to the condition of valorisability, accessibility and separability.

In addition to the engineering problems of dismantling presented above, there exist critical problems on the "back system": tools, the time of dismantling and then the costs (labor, industrial equipment, energies etc).

Das (2000) indexes the costs relating to the treatments and dismantling process: (1) collection; (2) sorting; (3) product handling; (4) disassembly training for the workers; (5) disassembly; (6) treatment of the parts and materials. 


\section{Design for Remanufacturing: What performances can be expected?}

It is noted that "Design for Disassembly" and "Design for Recycling" have common parts. In entry, the use of the recycled materials reduces the quantity of necessary materials. In Output, the recycling of non-desired production and scrap reduce the quantity of waste resulting from the production process or of energy consumption.

Coppens (1999) proposed the integration of a tool specialized in the design process, to take into account the recycling constraints for vehicles end of the life (VHU). If recycling appears tempting, it has should be considered additional cost and impact indeed the consumption of energy cannot be decreased effectively because additional energy is used in the processes of the recycling of materials. Economically, recycling decreases the benefit of the companies because of the additional costs due to the process of recycling. Consequently, simple recycling could not be a good strategy for some product end-of-life (Umeda, 2000).

\section{Design for Modularity}

"Design for Modularity" is an approach aiming at subdividing a system in smaller parts which can be created in an independent way and then used in various systems. In addition to the reduction of the costs, the modularity offers flexibility in the design (the addition of new technical solutions).

The literature on the topic shows that strong competition on the market pushed the companies to design a larger variety of products to satisfy the customers' needs. However, the frequent variations of product specifications lead to an assembly and a dismantling of the components and modules increasingly complicated. In the study of Tseng (2008), were added to the graph of the connections some attributes allowing the designers to characterize the connections between components during the design process. With a genetic algorithm, it is then possible to gather the components, to consider their modifications taking into consideration need for the modular concept (Tseng, 2008).

Kimura (2001) proposes a modular design method which takes account of the successive generations of products based on common functionalities and similar life cycles. Umeda and $\mathrm{Al}$ (2008) consider that the modular concept is important to improve the design of life cycle, for example, maintainability, upgradability, reutilisability and recyclability. They propose a modular design methodology which rises from the structure of the modules based at the same time in the characteristics of the life cycle and geometrical information. Considering the whole life cycle of a product, the components which undergo the same life cycle should be gathered in a module. These modules can then undergo maintenance and processes of recycling without disassembling. That led to an easy management of the components throughout the life cycle and to the reduction of the environmental impact and the costs of logistics and recovery.

But the modular concept implies also constraints. A module must be made up of elements belonging to the same group. The violation of this constraint can radically destroy the advantages of the modularity, such as the desassemblability, the reutilisability, and the recyclability. Moreover, one module should not be geometrically surrounded by components belonging to another group; if not, the element cannot be extracted without dismounting the module; this violation of this constraint reduces also the advantages of modularity (Umeda, 2008).

\section{Design for Remanufacturing}




\section{Tchertchian N, Millet D\& El Korchi A}

The origin of Remanufacturing goes back to the World War II during which many products used were remanufactured in order to maintain the company in operating condition. During last decades, the concept and the activity of remanufacturing were largely spread in the industrial and academic fields.

There exist various synonyms of the remanufacturing. Thus, in the sector of the remanufacturing of the automobile components, the term "rebuilding" or standard exchange is preferred. In the same way, the manufacturers of tires are called "retreaders", while the remanufacturer of toner cartridges regards himself as "rechargers" (Lund, 1996). If the "rebuilding" of the product is not extensive, i.e., if only some parts must be replaced, the terms of Reconditioning/"refurbishing" is more suitable: the product is then only remanufactured with its original specification (Ijomah, 1999). In the literature, we find a robust definition of the remanufacturing:

- "Remanufacturing is the process of restoring discarded products to useful life." (Lund, 1996)

- "Remanufacturing is "The process of returning a used product to at least Original Equipment Manufacturer performance specification and giving the resultant product a warranty that is at least equal to that of a newly manufactured equivalent." (Ijomah, 2002)

The industrial sector which has the most experience in the field of the remanufacturing is automotive industry (for example the clutch of car, the starter...) but more and more, the remanufacturing is propagated with other sectors, like those of the electrical appliance, toner cartridges, photocopiers, apparatuses, of the machine tools, cell phones etc.

In the state of the art, we observe that the remanufacturing is currently mainly centered on the following aspects:

- The evaluation of the remanufacturability and the redesign of the product, concerning architectures, connections, joints, modules, materials etc., to facilitate the processes of remanufacturing (Van der Laan and Salomon, 1997) (Zwolinski2006) (Gray and Charter, 2007) (Ijomah, 2007),

- Improvement of the processes of remanufacturing (dismantling, inspection, cleaning, reconditioning, re-assembly, etc.) in terms of technologies of treatment (dismantling, inspection, cleaning, reconditioning, re-assembly etc.), of equipment etc. (Lund, 1996) (Steinhilper, 1998),

- Coordination between the remanufacturing and the business (functional sale, rent service, etc.). (Sundin, 2004) (Mont, 2002) (Mont, 2006),

- Coordination between the remanufacturing and reverse logistics (Bras and Intosh, 1999) (Mont, 2006) (Lindahl, 2006),

- Benefit analysis of the remanufacturing from economic and environmental point of view. (Kerr, 1999) (Ijomah, 1999) (Sundin, 2004) (Smith and Keoleian, 2004) (Kerr and Ryan, 2001).

Many research in the field of the remanufacturing is focused on one or more abovementioned aspects. In all the connections, one of the most significant work is that of Robert Lund at the end of the years 1970 - beginning of the year 1980 which launched the debate around the benefit of the remanufacturing and the many aspects which must be considered including the selection of the products, the marketing strategy, the technology of reconditioning, the financial aspects, the organizational factors, and the legal considerations (Lund and Skeels, 1983).

Another researcher considered in this field, Steinhilper (1998) illustrated the appropriatenesses and the challenges remanufacturing: 
Design for Remanufacturing: What performances can be expected?

- A strategy of business based on the remanufacturing can support the world of manufacture by opening new business appropriatenesses in the service market of sales by creating new solutions with total costs lower for their customers,

- $\quad$ The manager of waste will appreciate if the remanufacturing can generate a profitable business in closed loop to replace an expensive process of elimination,

- The engagement of the public authorities for a strategy privileging the remanufacturing must allow the development of new markets and job creation,

- The economists regard the market of the remanufacturing as having a strong potential, the companies engaged today in this way being regarded besides as "hidden champions" in industry,

- For the consumers, the remanufacturing is not only more ecological, but also more economic because it is then possible to reach products with a technology updated with an affordable price.

"Design for remanufacturing" relates to not only the product but more largely the rendered service and can bring to reconsider the business model company.

Gray and Charter (2007) identified the constraints to characterize the most useful methods "Design for "the $\mathrm{X}$ "" ("X" represents for example dismantling, cleaning, the inspection, etc.). In other work (Kerr and Ryan, 2001), the concept of eco-effectiveness is used to evaluate the economic and environmental benefit remanufacturing.

Figure 1 : The generic process of remanufacturing according to Steinhilper (1998)

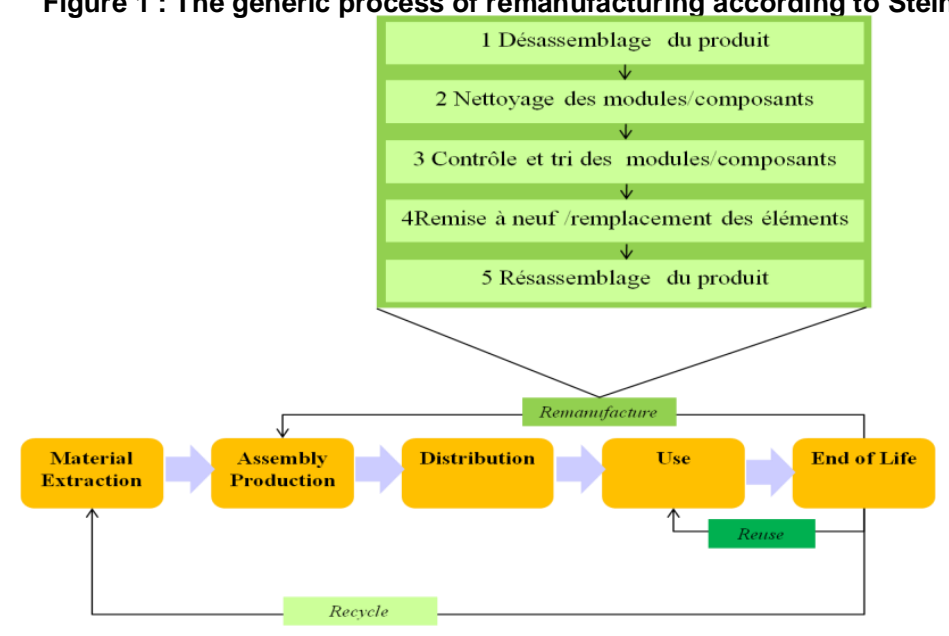




\section{Tchertchian N, Millet D \& El Korchi A}

The democratization of the remanufacturing in industry runs up against obstacles because it has also constraints for the industrialist.

The sensitive products to the change of tendencies and which evolve very quickly are little adapted to the remanufacturing because the users prefer the new products, it does not matter the quality and the cost of the alternative remanufactured.

Practices such as the patents, the intellectual property laws and anti-competitive can also block the remanufacturing. For example, some manufacturers of printers designed their inkjet cartridges so that they are auto destructive when they are empty what prevents to them remanufacturing (Ijomah, 2007).

The processes of remanufacturing are difficult to manage because of uncertainties, like those on times and the operations of treatment or those on the choices of the quantity and the quality of the components to be recovered. Moreover, flows which feed the process of recovery are also unertain in quantity, quality, and terms of date (Van Nunen and Zuidwijk, 2004).

In a survey of the American car industry, Hammond and Al (1998) identified that the costs and the availability of the part (including the modules) are principal concerns for the remanufacturers. However in the last decade, the variety of the products increased significantly because of a faster development of products, of an exacerbated and mondial competition bringing to an increased segmentation of the product ranges, a personalization of product of mass production. That led to an increase in the variety and a reduction in volumes of the parts causing a lower availability of the parts of replacement. In other words, the problem of the availability and the replacement cost of part are strongly related to the problem of the diversity of the products. The remanufacturor must deal with small batches of products including a range of alternatives and generations, which complicates the operations of remanufacturing, the management of flows, and the evolution of the tools for dismantling and processes of assembly...

\section{The problematic to assess the performance of the Design for Remanufacturing}

The review of literature made here watch in particular that the methods Design for Remanufacturing have advantages in their capacity to take into account the needs for the designer (the DfX methods are structured around a mode of reasoning very close to that implemented by the designer) and to a lesser extent on economic dimension (the economic evaluations do not take into account the concept of multiples life cycle). They have however weaknesses on customer dimension (the DfX approaches in general regard the functionalities of the product as being fixed; a fortiori, they do not take into account the update of the functions which could take place on the second life cycle of the product and on the following cycles) like on environmental dimension (in the methods DfX, the environmental evaluations are generally centered on the reduction of waste; they seldom integrate a variety of environmental impacts categories what is a requirement for a rigorous work in eco-design). The continuation of the article aims at filling a lack of information on the performance of the remanufacturing (environmental and economic). Indeed, the study of the performances requires the taking into account of the number of life cycles of the product, of the number of remanufactured modules, the localization of the remanufacturing operations, the range considered, the number of center of regrouping... 
Design for Remanufacturing: What performances can be expected?

\title{
2 Modélisation des scénarios du cycle de vie
}

\author{
2.1 Glossary \\ E : Environmental impact \\ C : Cost \\ $\mathrm{G}_{\mathrm{N}} \quad$ : Annual economic gain for the manufacturer \\ T : Total Cost \\ X : Remanufacturables Modules Scenarios \\ $\mathrm{Y} \quad$ : Supply Chain Scenarios \\ $\mathrm{n} \quad$ : Number of cycle \\ $\mathrm{z} \quad$ : Duration of the leasing agreement (Years) \\ A : : Supplying modules \\ M : Product assembly or reassembly \\ $\mathrm{P} \quad$ : Production (Extraction + Manufacturing) \\ D : Distribution \\ U : Use Phase \\ F : : Product End Of Life \\ Un : Unitary \\ Lg : : Supply Chain \\ $m \quad$ : Remanufacturables modules according scenario $\mathrm{X}$ \\ $\bar{m} \quad$ : Non remanufacturables modules according scenario $\mathrm{X}$ \\ $p \quad: m$ and $\bar{m}$ assembled (product) \\ Fr $\quad$ : France \\ $\mathrm{Ch} \quad:$ China \\ $\mathrm{Ch} / \mathrm{Fr} \quad$ : From China to France \\ Fr/Ch : From France to China
}

\subsection{Modeling of the life cycle parameters}

To model the various scenarios, we defined the parameters of the life cycle.

Actually, there exist several alternatives of life cycles integrating the parameters of the "remanufacturing". For example the number of modules remanufactured, lifespan of the modules and the machine, the number and the distribution of grouping centers, the re-use of the modules in the same range or various generations of products, etc. To simplify the modeling of the product life cycle, we focused ourselves on the three principal parameters: the number of remanufactured modules $(\mathrm{X})$, the number of cycles $(\mathrm{N})$, duration of cycles $(\mathrm{Z})$, and the place of the remanufacturing center $(\mathrm{Y})$.

\section{Parameter 1: Number of remanufacturable modules}

The definition of the remanufacturables modules is based on multiple criteria:

Technical feasibility - Environmental respect - Economic profitability. However before doing any evaluation, the modules, potentially remanufacturables must be given to build the various scenarios in order to choose the strategy which will answer the aims of the study.

We chose, for the case study in the next paragraph, seven modules to combine the various scenarios of remanufacturing. By considering the level of disassembling, we built the 
scenarios from 1 to 7 . For the electronic modules, scenarios 8 and 9 are individually defined. Scenarios are defined according to the following relations:

Scenario 0: $S^{\mathbf{0 ; 1} 1^{*}}$ corresponds to WEEE scenario (no module is remanufactured)

Scenario i: $S^{i, n^{*} z}=\sum_{k=1}^{7} M_{k}, \mathrm{i}=1 . .7$

Scenario 8: $S^{8 ; n^{* z}}=M_{4}+M_{5}+M_{6}$

Scenario 9: $S^{9 ; n^{* z}}=M_{1}+M_{4}+M_{5}+M_{6}$

\section{Parameter 2: Number of cycles and duration of cycles}

Concerning the parameter of the number of cycles and duration of cycles, we considered 4 possibilities: 2 cycles of 4 years or 5 years (Figure 2); 3 cycles of 3 years or 4 years (Figure 4). The stages of each cycle and their composition are defined in the following figures:

Figure 2 : Scenario with 2 Life cycles

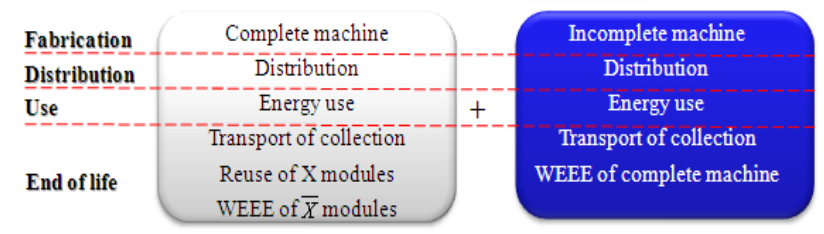

Figure 3: Scenario with 3 Life cycles

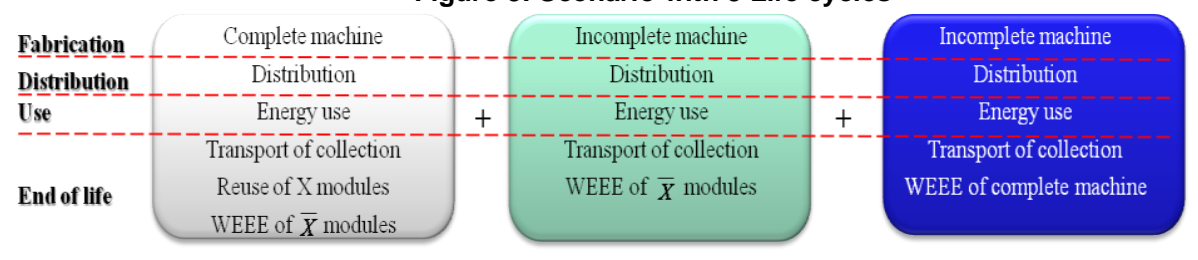

\section{Parameter 3: location of remanufacturing center}

We distinguished 2 cases:

- Case of remanufacturing in France and establishment of the chain of reassembly in France:

The modules extracted the remanufacturing in France are assembled with machines incomplete coming from the center of assembly in China.

- Case of remanufacturing in France and re-assembly in China:

The modules extracted the remanufacturing are returned towards China and are reassembled with the new modules in the same center of assembly of the new machines in China.

\subsection{Model for the environmental assessment}

The modeling of a life cycle of a product whose certain modules are re-used once is carried out with SIMAPRO® thanks to functions REUSE and DISASSEMBLY. The modeling of several cycles of use using a LCA software is different starting from the second cycle: indeed starting from the second cycles the modeled system depends on the 


\section{Design for Remanufacturing: What performances can be expected?}

parameters imputed by the user according to the number of life cycles, of the end-of-life of the modules (re-use or recycling) or of the logistic scenario (Tchertchian, 2009).

The systems modeled starting from the 2nd cycle are systems which in "theory" are manufactured without the modules that one wish remanufacture. Of course it is about a fantastic notion because in reality the re-used modules are assembled at the same time as the other components, but the impact of the manufacture of this module "is avoided" by re-using it. The coefficients $\alpha_{\mathrm{k}}$ : Recycling rate of material $\mathrm{k}$ and $\beta_{\mathrm{m}}$ : Reuse rate of module $\mathrm{m}$ give an account of the materials transfers in a cycle and between two cycles. For example the material share which can be recycled in a cycle is reinjected in the following cycle as the transfer of material flow shows it in the diagram below Figure 4). That relates to the modules which are not remanufacturables but also reusable modules whose the performance and quality standards are not respected.

In order to have an analysis detailed on the whole of the life cycle, we initially broke up the multiple cycles into phases: Production, Distribution, Use and end-of-life. The method of calculating used is the Method Eco Indicator 99 for all simulations because it makes it possible to obtain a single score which simplifies interpretations (method CML added with 4 complementary indicators, whose results will not be presented, was used in order to bring an "objective" support additional and thus to consolidate the results obtained with the method indicating Eco 99).

Figure 4: Model for the environmental assessment

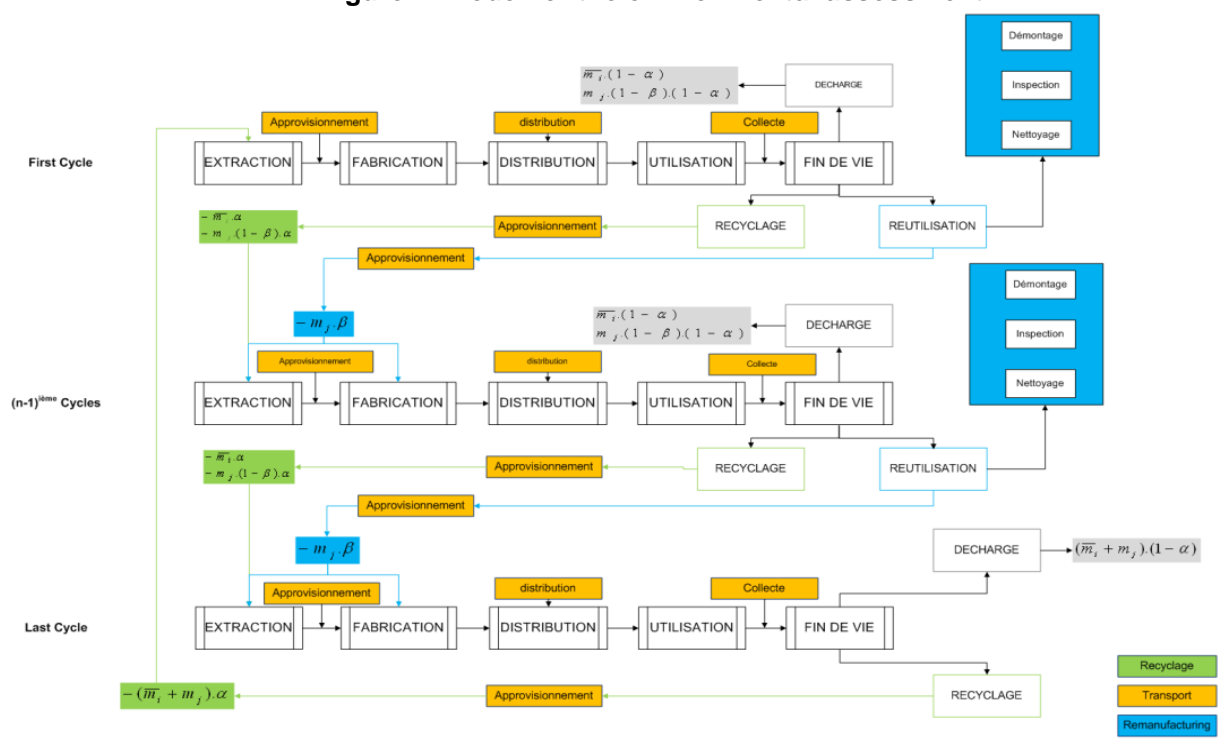

Below the modeling of the environmental impacts for the various scenarios:

$$
E_{\text {phase }(\bmod \text { ules }), \text { country }}^{\text {Sc-modulesycles }}
$$

Then we will enumerate all the elements for each scenario which one defined. 
Tchertchian N, Millet D \& El Korchi A

For example the Scenario $S^{\mathbf{O} ; \mathbf{1}^{*} z}$ (1 cycle of $\mathrm{Z}$ years, end-of-life undergoes DEEE) is the scenario of reference used to compare the various scenarios of remanufacturing:

\begin{tabular}{|l|l|l|l|l|}
\hline & Production & Distribution & Use & End of Life \\
\hline 1st cycle & $\begin{array}{l}E_{P(p), C h}^{\mathrm{O} ; 1^{*} z} \\
\begin{array}{l}\text { Production } \\
\text { (Extraction } \\
\text { +Manufacturing) of } \\
\text { one complete } \\
\text { machine in China }\end{array}\end{array}$ & $\begin{array}{l}E_{D(p), C h / F r}^{\mathrm{O} ; 1^{*} z} \\
\text { Distribution of the } \\
\text { complete machine } \\
\text { from China to France }\end{array}$ & $\begin{array}{l}E_{U ; 1^{*} z ; 1}^{\mathrm{O}} \\
\text { One cycle use of z } \\
\text { years in France }\end{array}$ & $\begin{array}{l}\text { Recycling of the } \\
\text { complete machine in } \\
\text { France }\end{array}$ \\
\hline
\end{tabular}

And the Scenario $S^{X ; 3^{*} z ; 2}$

( 3 cycles of 3 years or 4 years, Remanufacturing in China $(\mathrm{Y}=2)$ ) :

\begin{tabular}{|c|c|c|c|c|}
\hline & Production & Distribution & Use & End of Life \\
\hline $1^{\text {st }}$ cycle & $\begin{array}{l}E_{P(p), C h}^{X ; 3^{*} z ; 2} \\
\text { Production } \\
\text { (Extraction } \\
\text { +Manufacturing) of } \\
\text { one complete machine } \\
\text { in China }\end{array}$ & $\begin{array}{l}E_{D(p), C h / F r}^{X ; 3^{*} z ; 2} \\
\text { Distribution of the } \\
\text { complete machine } \\
\text { from China to France }\end{array}$ & $\begin{array}{l}E_{U(p), F r}^{X ; 1^{*} z ; 2} \\
\text { One cycle use of } z \\
\text { years in France }\end{array}$ & $\begin{array}{l}E_{F(m+\bar{m}), F r}^{X ; 3^{*} z ; 2} \\
\text { End of life of } 1^{\text {st }} \text { cycle: } \\
\text { reuse of m modules; } \\
\text { recycling of } \bar{m} \\
\text { modules ;transport of m } \\
\text { modules to China } \\
E_{D(m, F r / C h)}^{X ; 3^{*} z ; 2}\end{array}$ \\
\hline $2^{\text {nd }}$ cycle & $\begin{array}{l}E_{P(\bar{m}), C h}^{X ; 3^{*} z ; 2} \\
\text { Production } \\
\text { (Extraction + } \\
\text { Manufacturing) of } \\
\text { one incomplete } \\
\text { machine of } \bar{m} \\
\text { modules in China }\end{array}$ & $\begin{array}{l}E_{D(p), C h / F r}^{X ; 3^{*} z ; 2} \\
\text { Distribution of the } \\
\text { complete machine } \\
\text { from China to France }\end{array}$ & $\begin{array}{l}E_{U(p), F r}^{X ; 1^{*} z ; 2} \\
\text { One cycle use of } \mathrm{z} \\
\text { years in France }\end{array}$ & $\begin{array}{l}E_{F(m+\bar{m})}^{X ; 3^{*} z ; 2} \\
\text { End of life of } 2^{\text {nd }} \text { cycle: } \\
\text { recycling of } \bar{m} \\
\text { modules ; transport of m } \\
\text { modules to China }\end{array}$ \\
\hline $3^{\text {rd }}$ cycle & $\begin{array}{l}E_{P(\bar{m})}^{X ; C h} \\
\text { Production } \\
\text { (Extraction }+ \\
\text { Manufacturing) of } \\
\text { one incomplete } \\
\text { machine of } \bar{m} \\
\text { modules in China }\end{array}$ & $\begin{array}{l}E_{D(p), C h / F r}^{X ; 3^{*} z ; 2} \\
\text { Distribution of the } \\
\text { complete machine } \\
\text { from China to France }\end{array}$ & $\begin{array}{l}E_{U(p), F r}^{X ; 1^{*} z ; 2} \\
\text { One cycle use of } z \\
\text { years in France }\end{array}$ & $\begin{array}{l}E_{F(p), F r}^{O ; 1^{*} z} \\
\text { Recycling of the } \\
\text { complete machine in } \\
\text { France }\end{array}$ \\
\hline
\end{tabular}




\section{Design for Remanufacturing: What performances can be expected?}

\subsection{Model and assumptions for the economic assessment}

The objective of this study is to evaluate the cost of end-of-life of machine. This cost covers all the reverse logistic process since the recovery from the customer until the final treatment (remanufacturing) of the machine.

This study is based on the ABC method (Activity Based Costing) and it follows the following step. Initially, the identification of the principal activities which compose the reverse logistic process machines at the end of the contract; these activities were classified in four principal stages. Then, the resources mobilized by these activities are identified. Then, each resource to the activity, which consumes it, is assigned. Lastly, the activities developed with the cost price of the product end-of-life are assigned.

The use of the method ABC would make it possible to calculate the real costs of the "remanufacturing" by distinguishing it from the costs of recovery of the other machines at the end of contract or the representatives of the failures. It would also make it possible to identify the consumer activities of resources and which affect the profitability of the "remanufacturing". In order to study the profitability of the remanufacturing from the life cycle point of view we chose modules as the remanufacturing level like limit of the phase of end-of-life.

Beside the method ABC which allows a good indirect burden-sharing, we also carried out another calculation based the consideration of the wages charged which cover the majority of the indirect loads. An analysis of sensitivity which makes it possible to show the difference between the two methods of calculating was carried out at the end.

Ten scenarios of calculation of the cost of end-of-life of the product were analyzed. The constitution of the scenarios was based on the variation of the number of modules with remanufacturer. In scenario 0 , machine is sent directly from production/ remanufacturing center to the recycling center of without passing by any treatment. In the scenarios from 1 to 9 the machines are disassembled in order to recover the remanufacturables modules, the non remanufacturables modules are sent to the recycling center.

As we underlined previously the comparison of the various scenarios should not be restricted with the end-of-life phase but it must be led from the complete life cycle point of view. For this reason we constituted three different scenarios of life cycle by varying the configuration of supply chain and reverse supply chain. It is considered that the supply chain deals with the life cycle of the new machines (1st cycle) while the reverse supply chain treats the life cycles of the remanufactured machines (2nd and 3rd cycles). The supply chain and the reverse supply chain are made up of the five following phases: Provisioning - assembly or re-assembly - distribution - use - end-of-life.

Each of the three supply chain scenarios comprises the ten sub-scenarios of end-of-life treated previously. The costs of the sub-scenarios of remanufacturing as their profits compared to sub-scenario WEEE were modeled on two and three life cycles. Below we define the modeling of the costs and the profits for the various scenarios by

\footnotetext{
$C_{\text {phase }(\bmod \text { ules }), \text { pays }}^{\text {Sc-modules;cycles*années;Sc-sup plychain }}$
}

For example scenario 0 (WEEE), $\mathrm{Y}=1$ is defined by the following model: 


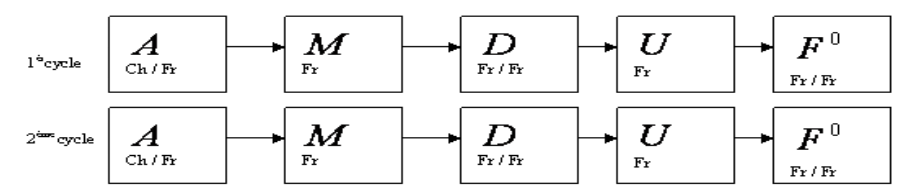

And the total costs of the scenario are defined by the following function:

$$
\begin{aligned}
& C_{T}^{0 ; n^{*} z ; Y}=C_{T}^{0 ; 2^{*} z ; Y}=C_{A(m+\bar{m}, C h / F r)}^{0 ; 1^{*} z}+C_{M(m+\bar{m}, F r)}^{0 ; 1^{*} z}+C_{D(p, F r / F r)}^{0 ; 1 * z}+C_{U(p, F r)}^{0 ; 1^{*} z}+C_{F(p, F r)}^{0 ; 1^{*} z} \\
& +C_{A(m+\bar{m}, C h / F r)}^{0 ; 1^{*} z}+C_{M(m+\bar{m}, F r)}^{0 ; 1^{*} z}+C_{D(p, F r / F r)}^{0 ; 1^{*} z}+C_{U(p, F r)}^{0 ; 1^{*} z}+C_{F(p, F r)}^{0 ; 1^{*} z}
\end{aligned}
$$

Formula for 2 cycles of 4 years becomes:

$$
C_{T}^{0 ; 2^{*} 4 ; Y}=2\left(C_{A(m+\bar{m}, C h / F r)}^{0 ; 1^{*} z}+C_{M(m+\bar{m}, F r)}^{0 ; 1^{*} z}+C_{D(p, F r / F r)}^{0 ; 1^{*} z}+C_{U(p, F r)}^{0 ; 1^{*} z}+C_{F(p, F r)}^{0 ; 1^{*} z}\right)
$$

In addition the scenario $\mathrm{X}$ of remanufacturing with $\mathrm{Y}=1$ is defined by the following model :

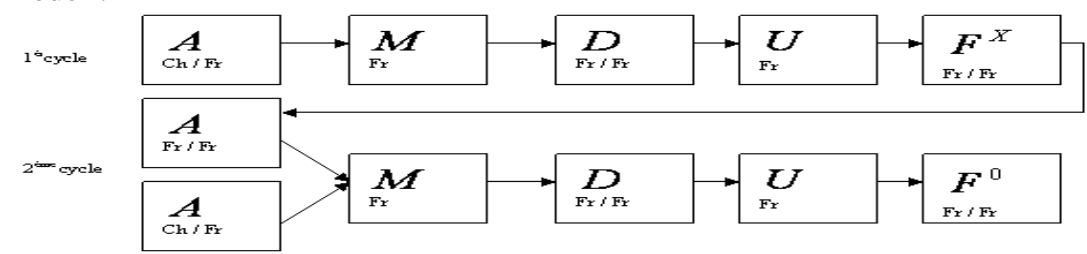

And the total costs of the scenario are defined, for two 4 years cycles, by the following function:

$$
\begin{aligned}
& C_{T}^{X ; 2^{*} 4 ; Y}=C_{A(m+\bar{m}, C h / F r)}^{X ; 2^{*} z}+C_{A(\bar{m}, C h / F r)}^{X ; 2^{*} z}+C_{A(m, F r / F r)}^{X ; 2^{*} z}+2 C_{M(m+\bar{m}, F r)}^{X ; 2^{*} z}+2 C_{D(p, F r / F r)}^{X ; 2^{*} z} \\
& +2 C_{U(p, F r)}^{X ; 2^{*} z}+C_{F(p, F r)}^{X ; 2^{*} z}+C_{F(p, F r)}^{0 ; 2^{*} z}
\end{aligned}
$$

The annual profit of scenario X compared to scenario 0 is given by the formula:

$$
\begin{aligned}
& G_{N}^{X, 2^{*} z}=\left(C_{U n(m+\bar{m}, C h)}^{0 ; 1^{*} z}-C_{U n(\bar{m}, C h)}^{X ; 2^{*} z}-C_{U n(m, F r)}^{X ; 2^{*} z}\right)+\left(C_{L g(m+\bar{m}, C h / F r)}^{0 ; 1^{*} z}-C_{L g(\bar{m}, C h / F r)}^{X ; 2^{*} z}-\right. \\
& \left.\left.C_{L g(m, F r / F r)}^{X ; 2^{*} z}\right)+\left(C_{F(p, F r)}^{0 ; 1^{*} z}-C_{F(p, F r)}^{X ; 2^{*} z}\right)\right) /(2 * z)
\end{aligned}
$$

\section{Evaluation of the Benefit of Remanufacturing: Case study}

\subsection{Definition of the remanufacturables modules}

For this study, the modules (regrouping of components fulfilling a function) were evaluated according to the criteria above in order to select the modules most suited to a remanufacturing:

- Technical criteria

- Environmental criteria

- Economic criteria

- Failure rate 
Design for Remanufacturing: What performances can be expected?

- Lifetime and reliability

- Easy to disassembly

- Easy to repair

- Modules cost

- Modules with high value added

- Extraction + Manufacture impact

- End-of-life cost (recycling, incineration, discharge, etc.)

- End-of-life impact (recycling, incineration, discharge, etc.)

According to these criteria we made a preselection of seven modules out of 12 on the whole. We then will analyze the interests of the remanufacturing module by module.

Figure 5: Modules definition

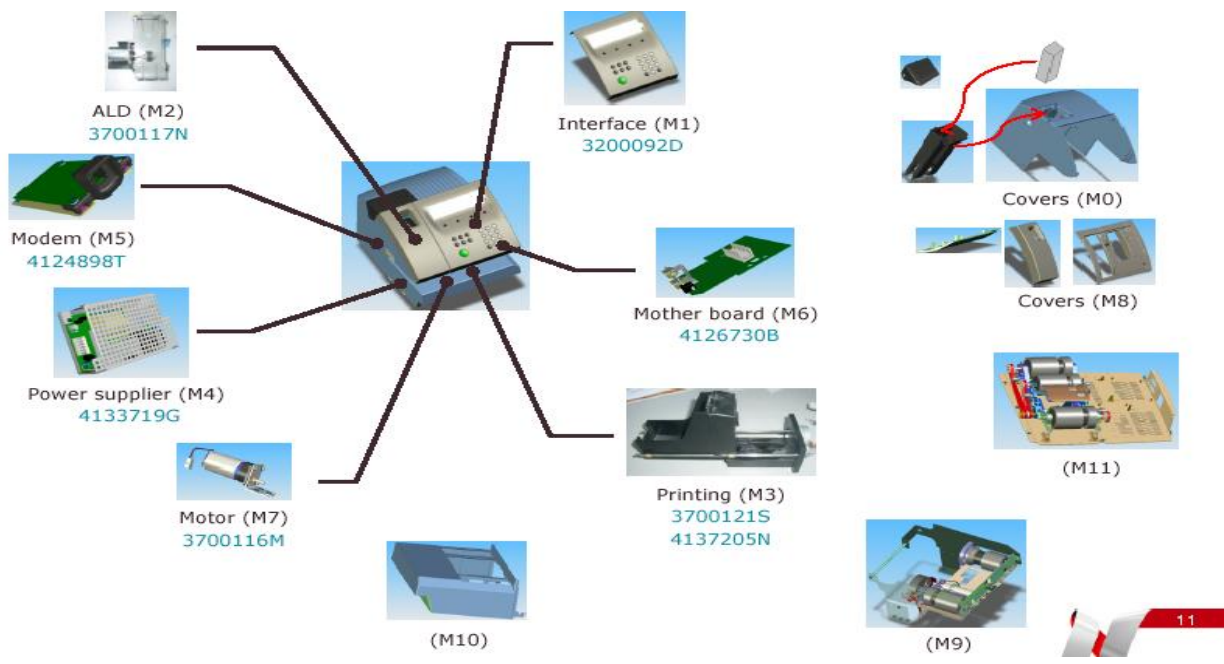

The product analyzed is a franking machine. The product is composed by 11 modules which 7 are considered as reusable

\subsection{Definition of life cycle scenarios}

The modeling of life cycle scenarios in the preceding paragraph makes it possible to model a total of 72 scenarios while varying the number of modules remanufactured the number and the duration of cycles and the localization of the centers of remanufacturing. The two examples below make it possible to give an account of logistic flows and material flow for a remanufacturing center located in France/China and for 2 or 3 cycles:

Figure 6: Remanufacturing M1+M2+M3+M4+M5+M6+M7 in France, 2cycles of 4 years 


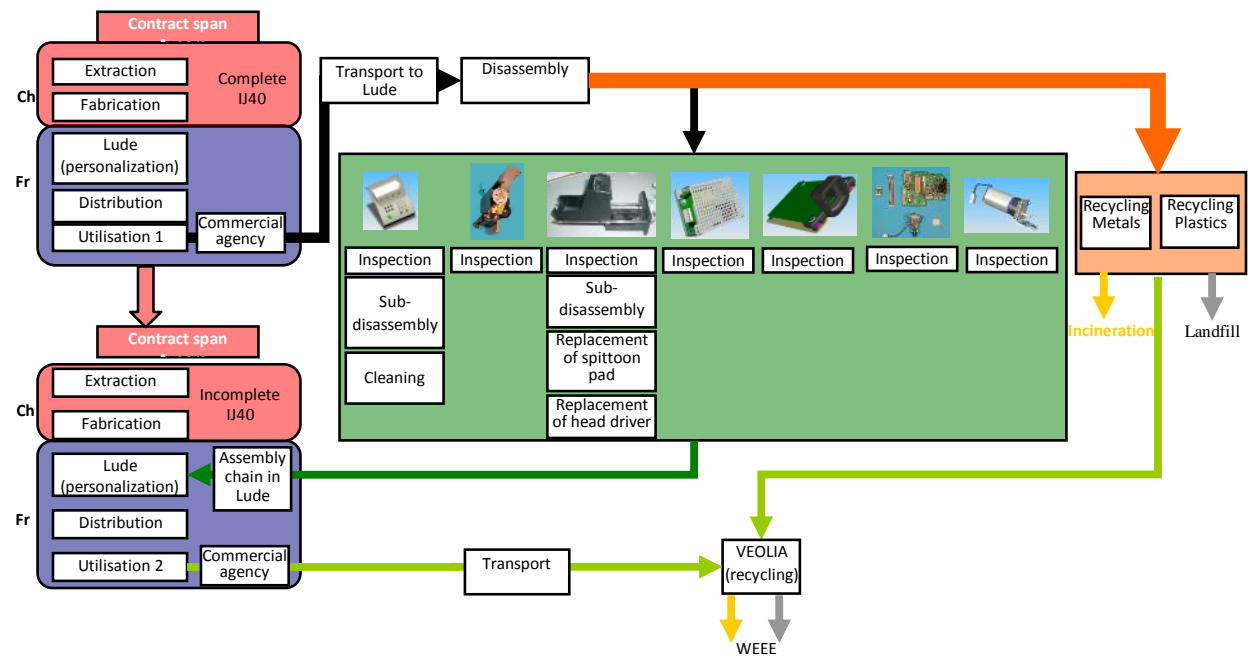

\section{Assumptions}

-The new machines are manufactured in China,

-The machines at the end of the contract are sent to the production center In Le Lude (France) to recover the modules remanufacturables.

-The modules extracted in remanufacturing center are assembled in the center remanufacturing in Le Lude with the new modules coming from China.

-The machines containing the modules remanufactured and new machines follow the same distribution system; the only difference which exists between the two circuits it is transport between China and France in order to place the new machines to France.

-The remanufactured machines and the new machines have the same customers and the same leasing agreements.

Figure 7: Remanufacturing M1, assembled in China, 3 cycles of 3 years

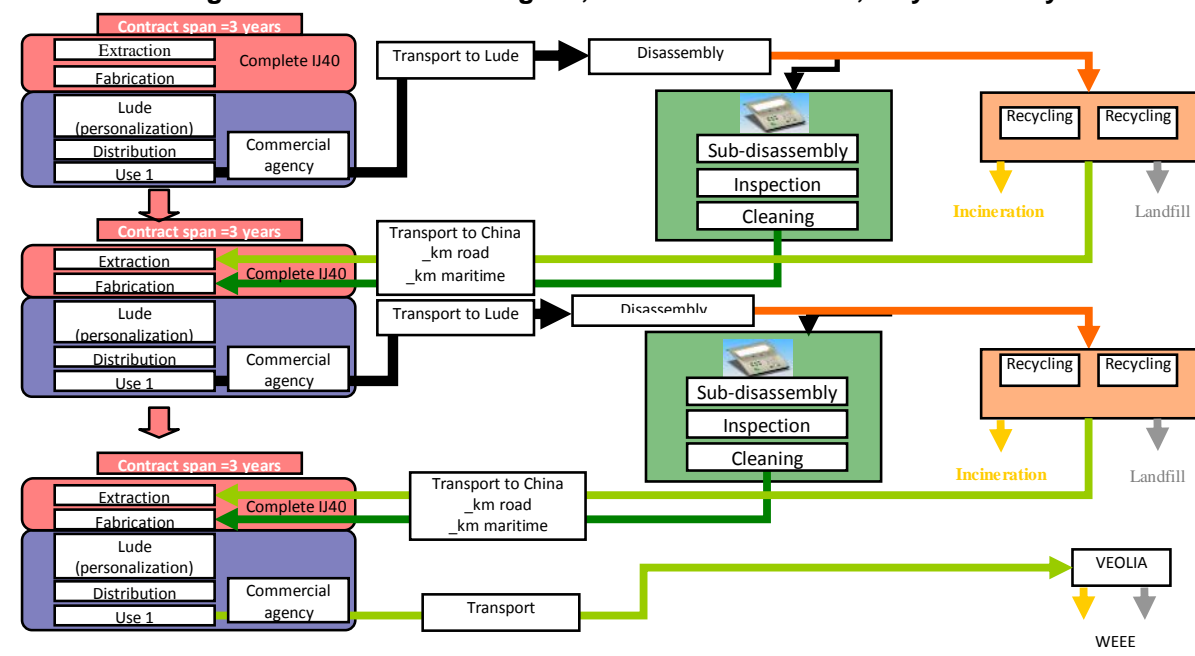


Design for Remanufacturing: What performances can be expected?

\section{Assumptions}

- The machines collected at the end of contract are sent in Le Lude (France) to recover the modules remanufacturables.

- The modules remanufacturables extracted in Le Lude are sent to the Production center in China.

-The machines containing the modules remanufactured and new machines follow the same distribution systemo

d-The remanufactured machines and the new machines have the same customers and the same leasing agreements.

\subsection{Environmental assessment}

WEEE regulation for the valorization of the electronic devices of categories 2 (small household appliances) recommends a valorization of the machine to a total value of $75 \%$, when one speaks about valorization it is necessary to take into account recycling, the recovery of parts but also the energy recovery (which consists in recovering the heat released by the combustion of waste).

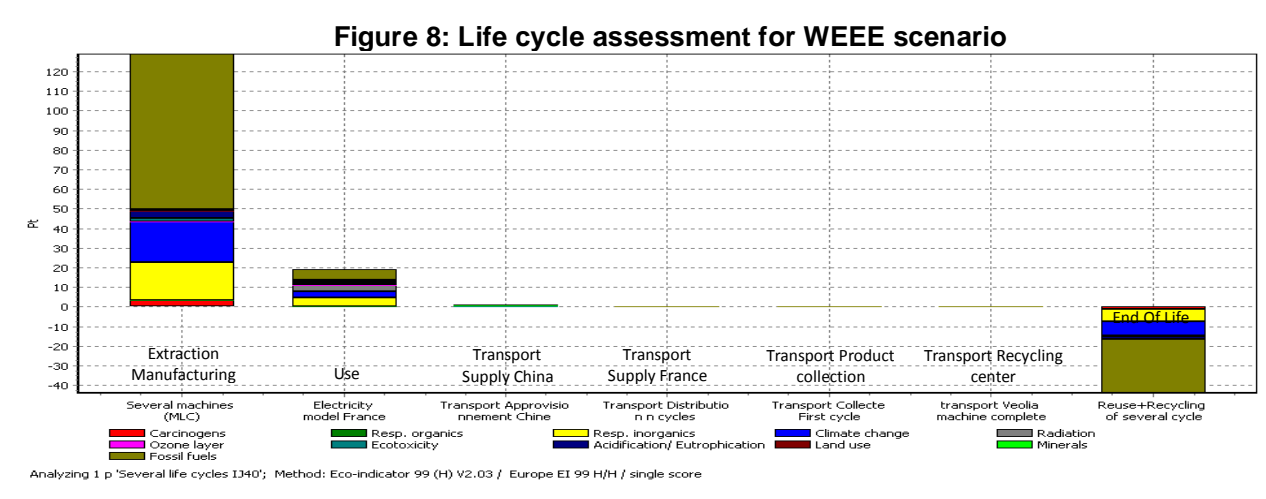

Modeling of WEEE scenario takes into account only the recycling of materials: Steel, plastics, aluminum and copper.

The extraction + Manufacture phase is more impacting, accounting for $62.3 \%$ of the impacts for a 4 years life cycle.

With the method Eco-indicator 99, the total environmental impacts (single score) for the Extraction + Manufacture phases are obtained by incorporating the impacts from the various indicators. Obviously, the five electronic modules (the interface, the food, the modem, the mother chart and the module of print) are more impacting. For these five modules, the major part of the impact concentrates on the category "Fossil fuels" (the greenish yellow part on Figure 8)

Figure 9: Environmental impact one complete product (Extraction + Manufacture) 
Tchertchian N, Millet D \& El Korchi A

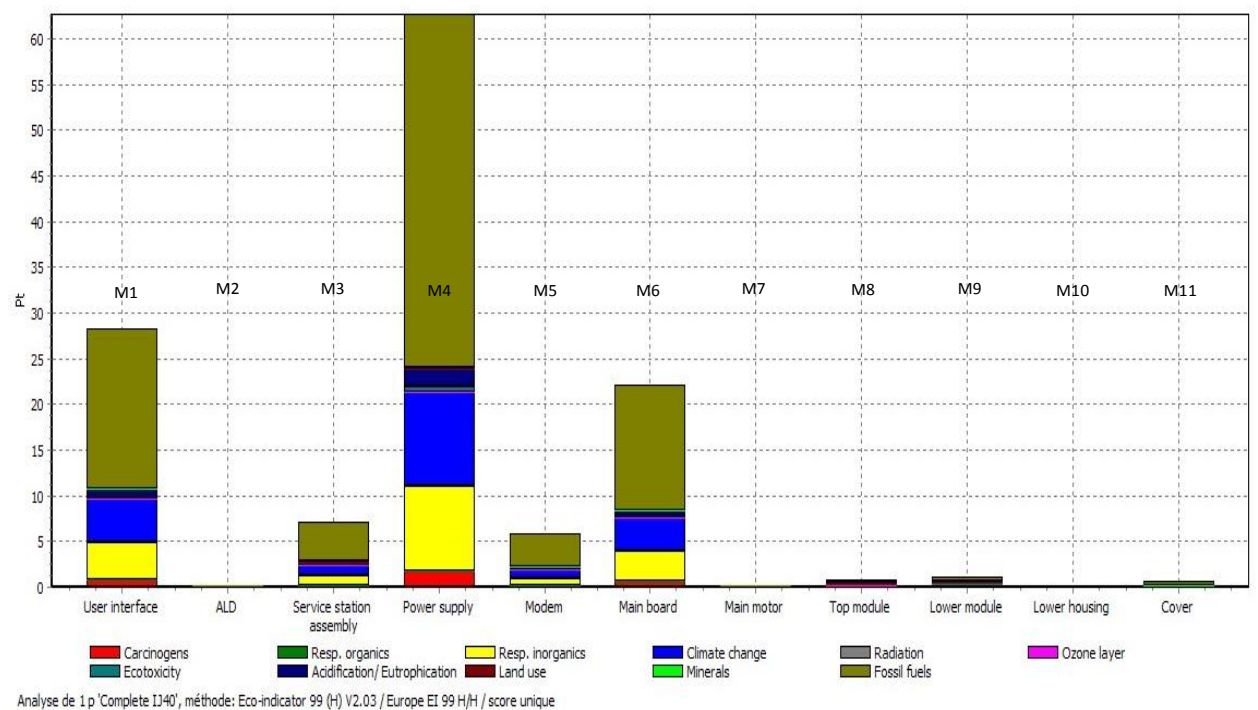

Figure 9 show also the intensity of the impacts for each module connected to its weight. Highest a mass impact of 227.8 point per kilo for the mother chart reaches.

\begin{tabular}{|l|l|l|}
\hline Module & Weight $(\mathbf{g})$ & Environmental impact (Pt) \\
\hline M1-User interface & 526 & 28,3 \\
\hline M2-ALD & 208 & 0,2 \\
\hline M3-Service station & 430 & 7,2 \\
\hline M4Power supply & 562 & 62,7 \\
\hline M5-Modem & 80,4 & 5,8 \\
\hline M6-Main board & 96,8 & 22,1 \\
\hline M7-Main motor & 344 & 0,2 \\
\hline M8-Top module & 1596 & 0,7 \\
\hline M9-Lower module & 2108 & 1,1 \\
\hline M10-Lower housing & 284 & 0,2 \\
\hline M11-Cover & 1117 & 0,7 \\
\hline
\end{tabular}

Figure 10: Total environmental impact for 36 scenarios (Remanufacturing in France) 
Design for Remanufacturing: What performances can be expected?

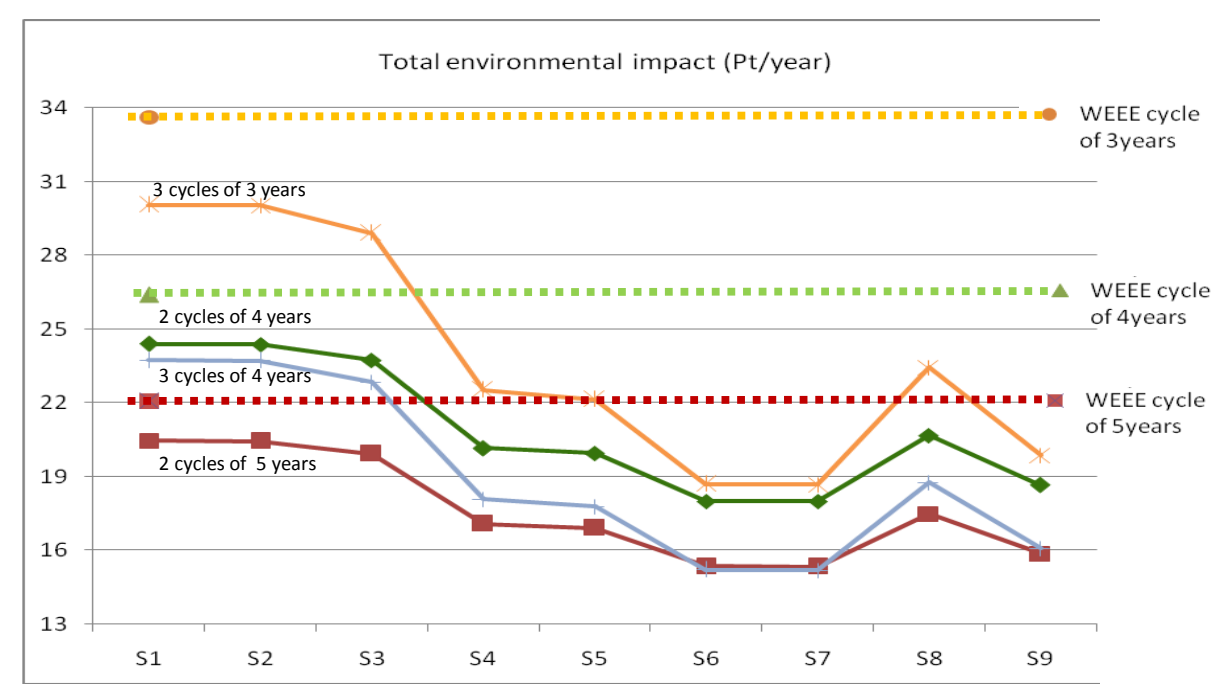

The summary of the results (Figure 10) shows that more the modules are remanufactured, less the generated environmental impact is important. In general the scenario of 34 years cycles, remanufacturing of 7 modules in France is optimal. In this scenario, the seven modules generate $98.0 \%$ of impact of the complete machine. Two re-uses out of three cycles for these seven modules bring a great profit for the environment. In more its utilization period over 12 years cause a drop in its annual impact.

At the same time, the scenario of 2 cycles of 5 years with remanufacturing of 7 modules in France has a performance very similar to the precedent. That is explained owing to the fact that the more one module lasts a long time in a cycle, the more it will be powerful for the environment.

Erreur ! Référence non valide pour un signet. summarizes the results of the 72 scenarios (9 scenarios of remanufacturing*4 Multiples Life cycle*2 Location for remanufacturing center). The remanufacturing is more powerful when it is carried out locally (France). When the center of remanufacturing is localized in France logistic flows are less impacting. The scenarios of remanufacturing are then compared with corresponding scenario WEEE. For 3 life cycles of 3 years and a remanufacturing center localized in France allows a profit of $44.4 \%$ compared to equivalent scenario WEEE.

Figure 11: Detailed results for the 72 scenarios 
Tchertchian N, Millet D \& El Korchi A

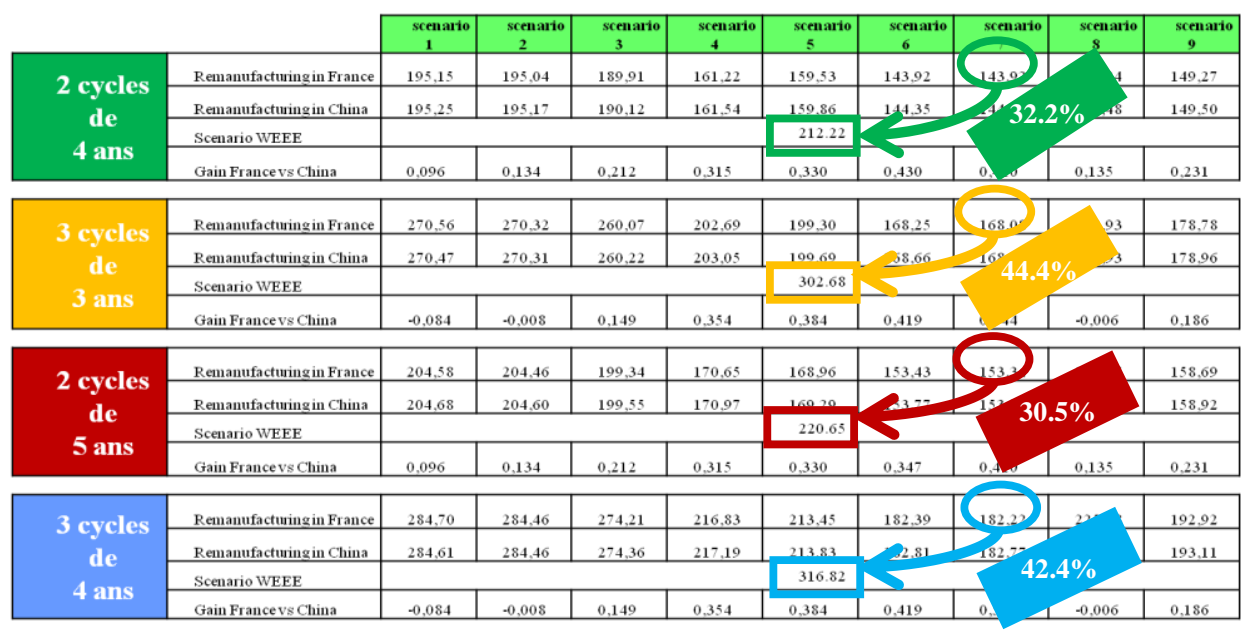

Erreur ! Référence non valide pour un signet. summarizes the results of the 72 scenarios (9 scenarios of remanufacturing*4 Multiples Life cycle*2 Location for remanufacturing center). The remanufacturing is more powerful when it is carried out locally (France). When the center of remanufacturing is localized in France logistic flows are less impacting. The scenarios of remanufacturing are then compared with corresponding scenario WEEE. For 3 life cycles of 3 years and a remanufacturing center localized in France allows a profit of $44.4 \%$ compared to equivalent scenario WEEE.

Figure 11 summarizes the results of the 72 scenarios ( 9 scenarios of remanufacturing*4 Multiples Life cycle*2 Location for remanufacturing center). The remanufacturing is more powerful when it is carried out locally (France). When the center of remanufacturing is localized in France logistic flows are less impacting. The scenarios of remanufacturing are then compared with corresponding scenario WEEE. For 3 life cycles of 3 years and a remanufacturing center localized in France allows a profit of $44.4 \%$ compared to equivalent scenario WEEE.

\subsection{Economical assessment}

The cost of each scenario is composed of the costs of the four following stages: stage of collection, sorting in Le Lude, treatment and recycling. The costs of the first two stages are constant because they are independent of the number of the modules with remanufacturer. The variation of the costs for the stage of treatment is mainly related to time spent to extract and treat each module.

Figure 12: Calculation of the overall costs ( 2 cycles of 5 years) 
Design for Remanufacturing: What performances can be expected?
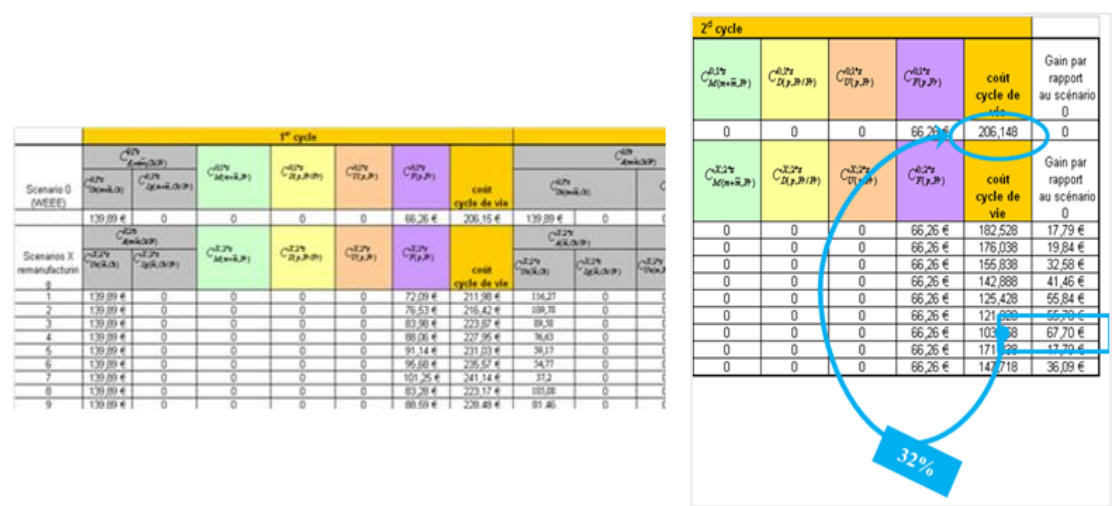

It is noticed that the cost of scenario 0 (WEEE) is lowest of all the scenarios because the machine does not undergo any treatment Lude. On the other hand, the scenario of remanufacturing 7 has the cost highest but it allows in against part recovery of a big number of modules strong added value and which can lead a second life cycle. One can conclude from that the comparison of the various scenarios should not be restricted with the phase of end-of-life but it must be led from the point of view of life cycle. The economic benefit compared to scenario WEEE lies between 25 and 35\% (Figure 12).

\subsection{Synthesis of economic \& environmental simulation results}

Among the 72 scenarios, we retained the scenarios corresponding to 25 years cycles with remanufacturing in France (they allow the best environmental performances according to the Figure 10). The 9 scenarios are treated on a hierarchical basis according to the environmental and economic profits compared to the scenario of reference WEEE.

Figure 13: Economic and environmental gain compared to WEEE (2cycles of 5 years)

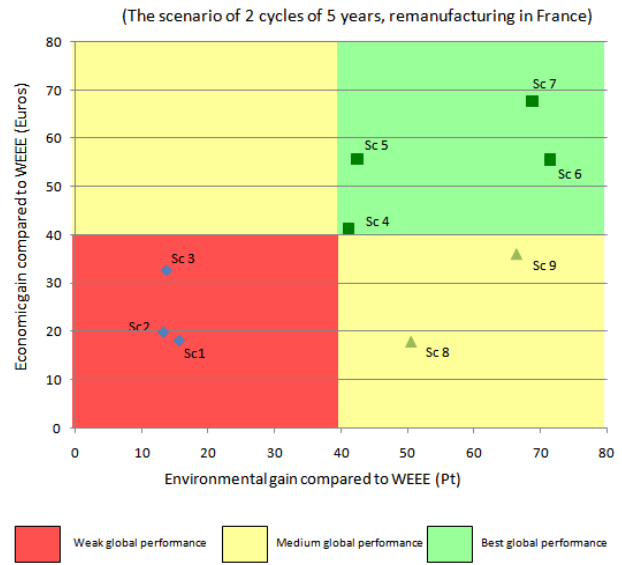

The scenarios of remanufacturing 6 and 7 are the powerful ones on the two criteria. In these two scenarios the number of modules re-used is largest. The other remarkable point 


\section{Tchertchian N, Millet D \& El Korchi A}

relates to the scenarios 8 and 9 , which integrate electronic modules, they are very good environmentally but their low costs of manufacture do not allow strong economic gains.

\section{Conclusion}

The state of the art on the DfX approaches supplies to the eco-designer solutions to improve the product. For example by adopting a modular architecture, by designing the product so as to return the components modules most easily extractable and by gathering the modules having identical end-of-life it is possible to optimize recycling and to re-use certain components modules. However the literature gives an outline of the operations necessary to the remanufacturing and logistic flows but it do not make it possible to emphasize the potentialities of the remanufacturing because of difficulty in apprehending the multiple products with life cycle. This difficulty can be explained by not taken into account of the methods of eco-design and the management of the RSC simultaneously. The study suggested in this article is pressed on a product whose diagram of distribution in France is the hiring. This product is recovered at the end of the contract and given in state. The exploratory field offered by this company enabled us to carry out evaluations economic and environmental complete system: Product and logistic structure. This experimentation enabled us to develop an economic model and an environmental model for products with multiple life cycles. From this model of simulations were realized. The simulations treated in this article give an account of the influence of the parameters: many remanufactured modules, many life cycles and duration of each cycle and geographical location of the center of remanufacturing. While taking into account simultaneously the characteristics of the product and logistic flows we managed to consider the economic gains and environmental for a mechatronic product on several life cycles. This case study carried out on franking machines associated with the state of the art of the DfX approaches highlights various dimensions of the problem of remanufacturing. All these elements reveal the need for placing at the disposal of the team of design, a method of assistance to the design of new concepts of systems remanufacturables.

\section{Aknowledgement}

We wish to thank Neopost industry to have opened to us carry from their production center and remanufacturing to France and to have given us access to the necessary informations to the realization of this study. We also thank members of MACPMR project as well as foundation CETIM and the ADEME for their financial support.

\section{Références}

Bras B., Intosh M. W. M. (1999) Product, process, and organizational design for remanufacture - an overview of research. Robotics and Computer Integrated Manufacturing, 15:167 - 78.

Coppens C. (1999) Méthode de conception en vue d'optimiser la valorisation des véhicules hors d'usage. ENSAM Paris.

Das SK, Yedlarajiha P, Narendra R. (2000) An approach for estimating the end-of-life product disassembly effort and cost. Int. J. Prod. Res.; 38(3):657-73.

Gray C., Charter M., Remanufacturing and Product Design. (2007) In: Farnham, editor. research report. UK: University College for the Creative Arts. 


\section{Design for Remanufacturing: What performances can be expected?}

Hammond R., Amezquita T., Bras B. (1998) Issues in the Automotive Parts Remanufacturing Industry -A Discussion of Results from Surveys Performed among Remanufacturers. International Journal of Engineering Design and Automation, 4:27-46.

Haoues N. (2006) Contribution à l'intégration des contraintes de désassemblage et de recyclage dès les premières phases de conception de produites. Paris: Ecole Nationale Supérieur d'Arts et Métiers Centre de Paris.

Ijomah W. (2002) Remanufacturing, doctoral thesis completed at University of Plymouth Enterprise.

Ijomah W.L., Bennet J.P. and Pearce J. (1999) Remanufacturing: Evidence of Environmentally Conscious Business Practice in the UK, Proceedings of IEEE International Symposium on Electronics and the Environment (IEEE-99), Danvers, USA, 11-13 May, pp 192-196.

Ijomah, W.L., McMahon, C.A., Hammond, G.P., \& Newman, S.T. (2007) Development of design for remanufacturing guidelines to support sustainable manufacturing. Robotics and Computer-Integrated Manufacturing, 23, pp.712-719.

Kerr W., Ryan C. (2001) Eco-efficiency gains from remanufacturing : A case study of photocopier remanufacturing at Fuji Xerox. Journal of Cleaner Production, 9:7581, Eco-efficiency gains from remanufacturing. A case study of photocopier remanufacturing at Fuji Xerox Australia, Journal of Cleaner Production, Vol. 9, pp 75-81.

Kerr W. (1999) Remanufacturing and eco-efficiency: A case study of photocopier remanufacturing at Fuji Xerox Australia. International Institute for Industrial Environmental Economics: Lund University, Sweden.

Kimura F, Kato S, Hata T, Masuda T (2001). Product modularization for parts Reuse in inverse manufacturing. Annals of CIRP, 50, pp.89-92.

Lindahl M., Sundin E., Sakao T. (2006) Shimomura Y. An Interactive Design Methodology for Service Engineering of Functional Sales Concepts - A potential Design for Environment Methodology. Proceedings of lce2006. Leuven.

Lund R, Skeels F. (1983) Guidelines for an original equipment manufacturer starting a remanufacturing operation, Government Report, DOE/CS/40192, CPA-83-8. Cambridge, MA: Masachusetts Institute of Technology, Center for Policy Alternatives.

Lund, R.T. (1996) The Remanufacturing Industry: Hidden Giant. Boston. Boston: Argonne National Laboratory study.

Mont O. (2002) Clarifying the Concept of Product-Service System. Journal of Cleaner Production, 10:237-45.

Mont, O., Dalhammar, C., Jacobsson, N. (2006) A new business model for baby prams based on leasing and product remanufacturing. Journal of Cleaner Production, 14(17), pp.1509-1518.

Steinhilper R. (1998) Remanufacturing - The Ultimate Form of Recycling: Fraunhofer IRB Verlag, Stuttgart.

Sundin E. (2004) Product and Process Design for Successful Remanufacturing. Department of Mechanical Engineering. Linköping, Sweden: Linköping University.

Tchertchian, N., \& Liang, H., Millet, D. (2009) The Influence of the Multiple Life Cycles on the Environmental Impact of a Product. Proc. ICED 2009 17th Int. Conf. Engineering Design.

Tseng H.-E., Chang C.-C., Li J.-D. (2008) Modular design to support green life-cycle engineering. Expert Systems with Applications, 34:2524-37.

Umeda Y., Nonomura A., Tomiyama T. (2000) Study on life-cycle design for the post mass production paradigm. AIEDAM (Artificial Intelligence for Engineering Design, Analysis and Manufacturing), 14:149-61, 2000.

Umeda Y, Fukushige S, Tonoike K, and Kondoh S. (2008) Product modularity for life cycle design. CIRP Annals - Manufacturing Technology, 57, pp.13-16. 
Tchertchian N, Millet D\& El Korchi A

Van der Laan, E., Salomon, M. (1997) Production planning and inventory control with remanufacturing and disposal. European Journal Of Operational Research, 102, pp.264-278.

Van Nunen J.A.E.E. and Zuidwijk R.A. (2004) Enabled Closed-Loop Supply Chains, California Management Review, Vol.46, No.2, Winter 2004, p40-54.

Zwolinski P, Lopez-Ontiveros M A, Brissaud D. (2006) Integrated design of remanufacturable products based on product profiles. Journal of Cleaner Production, Volume 14, Issues 15-16, Pages 1333-1345. 